\title{
Approval Plans: Vendor Responsibility and Library Research A Literature Survey and Discussion
}

The widely accepted approval-plan concept has moved from a lengthy period of discussion of selection responsibility to a few recent studies of the plans' cost, efficiency, and impact on research collections. An annotated list of articles from 1958 to 1972 traces this transformation and identifies the research studies. Responsibilities of vendors in advertising and promotion and in continuing service to libraries are discussed. Areas for further research and cooperative programs to apply research findings are proposed.

L LIBRARIANS WRITING AROUT APPROVAL PLANS are nearly unanimous in their support of the concept. It seemed, however, from discontinuous reading, that much of the discussion was offered by administrators who were concerned with theory, not with technique; that much of the widely expressed satisfaction was unsupported by critical study or research; and that the continuing influence of the originator and promoter, the vendor, was largely overlooked.

Therefore this literature survey. The discussion following the bibliography is restricted to plans for United States publications, although some articles in the survey treat both domestic and foreign plans as a single concept. United States plans, because they produce more books, seem to provoke more of the complexities. The discussion considers two problems-the performance of vendors offering the plans and the difficulties of acquiring unvolunteered

Ms. McCullough is assistant order librarian at Purdue University, West Lafayette, Indiana. books-and will suggest areas for further study.

\section{LITERATURE SURVEY}

Libraries with approval plans of their own will not find much in this list that is outside their experience. Almost every author has been cited by another; there is much in-breeding, a situation suggesting the need for more research.

Articles are in roughly chronological order, but those that relate to each other are grouped; literature was searched through mid-December 1971. Quotations pointing out technical problems and proposing research were deliberately chosen for that reason and are not to be construed as necessarily representing the author's principal thesis. Research surveys and in-house studies are indicated by an asterisk.

Early blanket orders involved selection, but in general return privileges were not a part of the agreement, giving rise to later charges of librarians abdicating their selection responsibilities.

1. Jacob, Emerson and Salisbury, Begel, "Automatic Purchase of University 
Press Books," Library Journal 83: 707-8 (1 March 1958).

Describes procedures used at Michigan State University library to acquire all books of university presses, receiving books directly from the presses, but using a jobber to place the standing orders and to consolidate billing to the library.

2. "Plan to Speed Pre-Viewing of Books by Libraries," Publishers' Weekly 179:31-2 (18 May 1959).

A news story describing in some detail the review-copy plan devised by Emerson Greenaway, first with Lippincott and later with other publishers. All books received were paid for, but librarians selected from books received those they wanted to catalog and to order in quantity for branches.

3. Merritt, LeRoy C. "Notes of Merritt," Library Journal 84:3548 (15 November 1959).

An editorial questioning blanket orders on the grounds that the selection process is abandoned and costs of cataloging more books offset cheaper acquisitions costs. Information is based on the 1957-58 report of the Ohio State University director of libraries.

3a. Oboler, Eli M. “' 'Get-'Em-All' Book Buying," Library Journal 85:1046 (15 March 1960).

Response to entry no. 3 , again arguing selection vs. completeness; “. . . surely there must be some reason why so many of their [i.e., university presses'] books get remaindered."

3b. Merritt, LeRoy C. "Notes of Merritt," Library Journal 85:1097 (15 March 1960).

Continues the discussion of the foregoing by noting responses from the library in defense of its plan. The library was ordering more than 90 percent of the total output of forty-seven university presses before the blanket plan; most of the remaining 10 percent were canceled by profile exclusions.

4. "The 'Get-'Em-All' Theory of Book Buying," Library Journal 85:3387-93 (1 Oct. 1960).

The first major article on blanket orders vs. selection, it is also a plea to critics to distinguish between receiving books earlier than usual and their subsequent review and selection. It is a symposium on the Greenaway plan, with Emerson Greenaway as a participant. ${ }^{2}$ Others were spokesmen for Lippincott and public, county, college, and university libraries. All but one (Oboler) felt that the advantages outweighed the disadvantages. ${ }^{3 a}$

4 a. "The Sanctity of Book Selection," Library Journal 85:3400 (1 Oct. 1960).

An editorial addressed to blanket-order critics. "There is always the danger that something holy can easily become a sacred cow. Those who wage indiscriminate war on behalf of the sanctity of book selection are in danger of precipitating this process."

4b. Stevens, Rolland E. "Down the Primrose Path-But Not All the Way," $\mathrm{Li}$ brary Journal 86:146 (15 Jan. 1961).

Response to entry no. 4 , principally Oboler's comments in $3 \mathrm{a}$ and 4 ; compares blanket orders for large research collections with a smaller library's continuation orders for monographic series.

From the first articles in 1958 to early 1961, the discussion of blanket orders centered on the charge that publishers were supplanting librarians as book selectors. After an apparent five-year hiatus, the subject again appears, but now discussion turns to the absolute necessity for rigid selection, and the topic begins to turn from "blanket orders" (all books kept, if not cataloged) to "approval plans" (books not selected can be returned). In addition to the emphasis on selection, criticism of vendors' services and complaints of internal problems for libraries begin to appear. Some of the problems are now being researched.

•5. "Quotes-Publishers, Computers, \& Consumers," Library Journal 91:1365 (15 March 1966).

A selection from the 1964/65 report of the University of California library, Los Angeles. It is the first to point to problems in the mechanics of the system: publishing, late receipt of books, and coverage:

Unfortunately the blanket order system is least effective for U.S. books because of the complexity of the American publishing 
business and the inexpertness of the American book distribution channels. Some test runs this year revealed shocking and apparently increasing delays in our receipt of currently published U.S. books. We had gone on the assumption that our own internal procedures, prior to ordering and after receipt, were the guilty elements, because libraries as nonprofit institutions are always easily accused of inefficiency. However, the oppressive delays appear to be in the market place and beyond our control. Moreover, the blanket-order system appears to be least effective for scientific and technical books, although the reason for this is not immediately clear.

6. Morrison, Perry D. "A Symposium on Approval Order Plans and the Book Selection Responsibilities of Librarians," Library Resources \& Technical Services 12:133-45 (Spring 1968).

Material originally presented at a College Division workshop during a Pacific Northwest Library Association conference at Couer d'Alene, Idaho, August 23, 1967, minutes of which appear in "College Division Workshop," PNLA Quarterly, Oct. 1967 , p. $29-30$. The principal author reviews the kinds of blanket orders and the reasons for using them. He cautions against heavy dependence on approval plans and states the need for further study of their immediate and long-term effects. His conclusion is that approval plans are basically beneficial but can produce automatic superficial selection methods that must not be allowed to supersede traditional librarian-faculty cooperation.

6a. Merritt, LeRoy Charles. "Are We Selecting or Collecting?" p. 140-42.

Concedes the value of approval plans, but questions the dealer's preselection: he works "from his definition of the word 'scholarly" and the books he considers not scholarly and does not send can be lost to the library completely because they may never be brought to the library's attention. His "contention is that the quality of the collections produced, not the promised increase in efficiency of ordering procedures is the true issue" (p. 140).

6b. Browne, Joseph P. "Can Blanket Orders Help the Small College Library?" p. 142-4.

Browne is opposed to blanket orders on the basis that "particularly in the small college library .... the one really professional library activity which we, as librarians, perform is that of book selection" (p. 142). He emphasizes the negative selection role a blanket order leaves to the librarian; i.e., the librarian rejects what he does not want after the initial selection by the jobber.

6c. Shepard, Stanley A. “Approval Books on a Small Budget?” p. 144-5.

Presents guidelines for determining whether a library can afford an approval plan, depending principally on a college's teaching commitment to the subject, the amount of publishing in that area, and whether a library's single-book ordering normally approaches the amount for total publishing.

7. "Blanket Order Plans Backed by Jackson," Library Journal 94:20 (1 Jan. 1969).

News report of a speech delivered by W. Carl Jackson, director of the Pennsylvania State University library, to eastern college librarians. One point not made generally is the advantage a blanket order provides of the library's gaining control of book funds previously held by departments. Problems cited include "delays in Library of Congress cataloging; the need to communicate to the faculty just what kinds of materials come automatically-and the need to explain to faculty members why a given book either was or was not accepted by the library."

8. Thom, Ian W. "Some Administrative Aspects of Blanket Ordering," Library Resources \& Technical Services 13: 338-46 (Summer 1969).

First to address in detail the problem of internal mechanical procedures in dealing with unverified bibliographical data, interim controls, storage, and selector traffic in the acquisitions area. He concludes that "it may be more costly to process unordered books than ordered ones" (p. 342).

8a. Rebuldela, Harriet K. "Some Administrative Aspects of Blanket Ordering: A Response," p. 342-5.

Offers suggestions for revising internal procedures, e.g., filing records and LC proofs by title to bypass the problem of unverified entries; Xeroxing rather than typing multiple $3 \times 5$ records. (See entry no. 22 , Anderson and Rebuldela.) 
8b. Thom, Ian W. "Some Administrative Aspects of Blanket Ordering: Rejoinder to a Response," p. 345-6.

Problems still are the acquisition unit's having to type its own purchase-recommendation forms for unordered books, normally submitted through other channels, and the problem of assignment of a location for each book to the various departments of the library, e.g., reference, browsing room.

๑9. Maher, Kathleen E.; Lane, Diana; Schmidt, Martha; and Townley, Charles. "How Good Is Your All Book Plan?" Norman, University of Oklahoma Libraries, n.d. (Mimeographed.) An internal research study run in the second quarter 1968/69 to determine whether the library's approval-plan vendor was producing, as promised, as much as 80 percent of the books within the week of publication or before the title's first appearance in trade bibliographies. Results were that the company was supplying 70 percent. The study found that university presses give the best service, followed, in order, by trade-scholarly publishers, publishers issuing fewer than five titles a year, and trade publishers. The study is described in detail by Axford. ${ }^{19}$

'10. Lane, David O. "Approval and Blanket Order Acquisitions Plans." Prepared for the Institute on Acquisitions Procedures in Academic Libraries sponsored by the University Library, University of California, San Diego, Aug. 25-Sept. 5, 1969. (Photocopy of typescript.) ED 043342.

Discusses selection vs. collection in the context of the distinction between blanket orders and approval plans and addresses the argument that it is easier to keep a book than to return it. "I believe it is a slur on librarians to say they would not return unwanted volumes" (p. 6). The article concludes with a survey of academic libraries to determine how many use the plans and what their experience has been. Questions and tallies of responses are included (p. 811). Twenty-five of the forty-six respondents were satisfied with their plans; of those expressing some dissatisfaction, complaints were "serials present problems; duplicates are received; too much junk received; too limited; takes too much time; pertinent books are not received; late re- ceipt; guidelines not followed; and billing and invoicing problems" (p. 9-10).

'11. Dudley, Norman. "The Blanket Order," Library Trends 18:318-27 (Jan. 1970).

Discusses the results of a survey on foreign and domestic plans of the then seventy-nine member libraries of the Association of Research Libraries to test the depth and breadth of the selection controversy and to "get some sort of picture of the impact of the phenomenon of the blanket order on research libraries' acquisitions policies and procedures" (p. 318). Results from fifty-two respondents are presented as discussion; the questionnaire and tallied replies are not included. The article details variations in plans, dealers' methods of announcing books, and methods of reviewing books received. Disadvantages, "neither as numerous nor as concentrated as the advantages" (p. 322), were uncertainty about receiving a specific title, marginal and ephemeral material received, expense of the program, loss of fiscal control, duplicates, and the quality of the dealer's book selection (p. 322-3). Dudley notes this fundamental aspect of approval plans: "A blanket order is a powerful tool; like any powerful tool it can be dangerous if not handled properly" (p. 326).

12. Rouse, Roscoe. "Automation Stops Here: A Case for Man-Made Book Collections," College \& Research $\mathrm{Li}$ braries 31:147-54 (May 1970).

Originally a paper read at the second seminar on approval and gathering plans, this is a widely discussed article that counters completely the general acceptance of approval plans. ${ }^{21}$ Rouse's thesis is that his librarians, with an average of 14.7 years on the staff at the time of his article, are much more knowledgeable about users' requirements than his vendor. He describes the library's unfortunate experiences with the internal technical problems created by the plan. Among these is the vendor-related problem of not knowing whether a book would be sent and of having to resort to the previously-used selection procedures to monitor the program.

Rouse also brings up a problem not previously discussed in the literature, that of over-statement of a company's capabilities by its representatives. The plan was in op- 
eration only four months, but he says, “. . . I shall admit to the possibility of unfairness in an experience of only four months but also point out the fact that this was one month longer than the agent said was needed ..." (p. 148). Because of the short time the plan was in operation and because of other specific statements, the article prompted numerous lengthy responses.

12a. "Letters," College \& Research Libraries 31:341-51 (September 1970).

The letters, Rouse's responses to the writers, and the original article must be read as a unit. Together they demonstrate that an approval plan is not a panacea and not for every library and that if an approval plan is undertaken the library must be prepared to give it constant attention; it is not automatic.

13. Wilden-Hart, Marion. "The LongTerm Effects of Approval Plans," $\mathrm{Li}$ brary Resources \& Technical Services 14:400-6 (Summer 1970).

Assesses approval plans as basic tools that will automatically supply the obvious, self-selecting kind of book, freeing bibliographers' time for collecting the more esoteric material. Then addresses the matter of how much they cost: ". . . it is difficult to assess how much more is spent on the system than is saved by professional staff no longer being expensively used as efficient clerks" (p. 402). Urges research into costs and the long-term effects on collection-building in libraries, both individually and nationally, with many specific questions to be answered. A significant article.

14. Meyer, Betty J., and Demos, John T. "Acquisition Policy for University Libraries: Selection or Collection," $\mathrm{Li}$ brary Resources \& Technical Services 14:395-9 (Summer 1970).

Distinguishes acquisitions policies for college libraries from those of research libraries, which have more diverse interests and larger budgets. Also introduces a factor that must be taken into account when approval programs are instituted: faculty attitudes toward departmental funds (see also entry no. 7 and Atkinson"20, 21). "The library which promotes any approval plan must face the important task of winning over the faculty members who can be notoriously conservative about 'their' libraries. Any pro- gram which appears to take money out of their hands and place it in a common pool for purchase of current materials is seen as a threat to the faculty's traditional control. It does not help, either, when a faculty member in a fairly conservative field sees some of the 'frivolous' titles other departments are spending money to purchase" (p. 398-9).

15. Evans, G. Edward. "Book Selection and Book Collection Usage in Academic Libraries," The Library Quarterly 40:297-308 (July 1970).

A study of four academic libraries compares the circulation of books selected by librarians, those selected by faculty, and those produced by blanket orders. Results were that "librarians selected more titles that were used than did faculty members or book jobbers, and faculty members selected more titles that were used than did book jobbers" (p. 301). Although the study was not intended to inquire into the reasons for the results, the figures did point to the differences in procedures of reviewing the books received: one person at one library, two at another, and teams of bibliographers at the other two. He concludes that rigid selection is essential and that selection must be done by persons for whom it is a primary responsibility, not added to other duties. Areas for additional research are noted on p. 307-8. The article is based primarily on the author's Ph.D. dissertation, "The Influence of Book Selection Agents Upon Book Collection Usage in -Academic Libraries." Graduate School of Library Science, University of Illinois, 1969. The abstract appears in Dissertation Abstracts International 30:3032A (Jan. 1970).

16. Taggart, W. R. "Blanket Approval Ordering-a Positive Approach." Canadian Library Journal 27:286-9 (JulyAug. 1970).

A descriptive article on both foreign and domestic plans intending "to place the positive benefits of a properly handled system on the record ..." (p. 286). He emphasizes the need for critical control on the part of the library selection staff: "The plans, although they are in a sense automatic, do not operate by themselves" ( $p$. 289).

17. Steele, Colin. "Blanket Orders and the 
Bibliographer in the Large Research Library," Journal of Librarianship 2: 272-80 (Oct. 1970).

Continues the point suggested by the Evans study, that subject specialists must be involved in helping to organize the approval-plan profile in the first place and in selection from the book shipments to maintain essential critical control of the program. ${ }^{15}$

18. Lyle, Guy R. The Librarian Speaking; Interviews with University Librarians. Athens: University of Georgia Press, 1970.

Subject bibliographers and approval plans are discussed in the interview with Robert G. Vosper (p. 175-6); other aspects of an approval plan-screening shipments, funding, coverage-are discussed with William P. Kellam (p. 74-5).

'19. Axford, H. William. "The Economics of a Domestic Approval Plan," College \& Research Libraries 32:368-75 (Sept. 1971).

"With respect to approval plans, what is needed at the present moment is a solid body of research which will calm some of the controversy by moving us from opinion and prejudice into documented facts" (p. 368 ). "Much of the published and unpublished research [views] approval plans largely in isolation from the total acquisitions and processing effort" (p. 369).

Axford studied processing costs and the use of staff time, specifically by each function in each technical service department, at five state universities in Florida, comparing the costs of books acquired by approval plan with those acquired by other means. The data "clearly support the contention that a blanket approval plan is an efficient method" and that "a well-managed approval plan can save at the minimum one fulltime position, with significantly higher savings possible depending on variances in internal procedures" (p. 371).

The project also included a vendor-performance study for university-press titles similar to Maher's, which he describes in detail. ${ }^{9}$ Results indicate faster and more complete coverage in the libraries with approval plans. The study was also presented at the third seminar on gathering and approval plans. ${ }^{22}$ 19a. DeVolder, Arthur L. “Approval Plans -Bounty or Bedlam?" Publishers Weekly, 202:18-20 (3 July 1972). A discussion of philosophy and practice, plus details of changes the library made to meet selection problems.

Three symposia have been convened to discuss approval plans exclusively, both foreign and domestic. Proceedings of the first two have been published; the third is due shortly. These three books provide a comprehensive survey of many aspects of the entire subject, including discussion by dealers' panels. The first two have appended material describing the programs and services of jobbers offering foreign and domestic plans, and the first has examples of profiles.

20. Sypers-Duran, Peter, ed. Approval and Gathering Plans in Academic Libraries. Published for Western Michigan University by Libraries Unlimited, Littleton, Colorado, 1969. (Proceedings of the International Seminar on Approval and Gathering Plans in Large and Medium Size Academic Libraries, Western Michigan University, 14 Nov. 1968.)

Contents:

'Atkinson, Hugh C. "Faculty Reaction to an Approval Plan at the Ohio State University." p. 30-40.

Bright, Franklyn F. "Blanket Orders with Foreign Dealers." p. 43-9.

Edelman, Hendrik. "Joint University Libraries and Blanket Orders." p. 12-16. p. $75-8$.

Hanlin, Frank. "Summary Statement."

Loreck, Richard. "Approval Plans Can Be Successful.” p. 4-7.

Sullivan, Howard A. "How to Make a Patchwork Quilt Into a Blanket; the Agony of Transition." p. 21-26.

20a. Rosenberg, Betty. "Acquisition Plans," review of Approval and Gathering Plans in Academic Libraries, in Library Journal 95:2237 (15 June 1970).

21. Spyers-Duran, Peter, and Gore, Daniel, eds. Advances in Understanding Approval and Gathering Plans in Aca- 


\section{4 / College \& Research Libraries • September 1972}

demic Libraries. Kalamazoo, Western Michigan University, 1970. (Proceedings of the Second International Seminar on Approval and Gathering Plans in Large and Medium Size Academic Libraries, Western Michigan University, 30-31 Oct. 1969).

Contents:

Atkinson, Hugh C. "Faculty Appraisal of an Established Approval Plan." p. 99106.

Boss, Richard W. "Automation and Approval Plans; Vendor-Library Cooperation." p. 19-29.

Boyer, Jean W. "Selective Duplication and Approval Plans.” p. 85-94.

Ferris, H. Donald. "Automated Selection of Duplicate Titles Through Approval Plans." p. 67-77.

Gore, Daniel. "Understanding Approval and Gathering Plans." p. 3-17.

Hamlin, Arthur T. "Summary Statement." p. 135-6.

Harris, Thomas C. "Book Purchasing or Book Selection; a Study of Values." p. 53-56.

Herling, Eleanor. "Approval Plans, Special Collections, and Kindred Matters." p. 63-5.

Rouse, Roscoe. "Automation Stops Here.” p. 35-48. (See also entry no. 12.)

21a. Melcher, Daniel. "Approval and Gathering Plans," Melcher on Acquisitions. Chicago, ALA, 1971. p. 109-16.

A description of approval plans written from the view of a publisher and bookseller, information for which was gathered at the second seminar. ${ }^{21}$ Some of his comments concerning vendors:

He may ... sense a new mandate regarding speed of delivery (p. 112).

Needless to say, the test of a gathering plan is not whether it provides the best discount, but whether it provides the books (p. 111).

The greatest gain ... seems to lie in the way the suppliers have risen to their new responsibilities. Formerly they could feel that they'd done their part when they had sent what they could and reported on the balance (p. 112).

Any wholesaler who accepts a blanket order contract ... accepts a new (and defined) type of responsibility. Like the library book-selection staff itself, he may have for the first time a really precise defi- nition of what the library wants from him -and means to get. And he will be up against a staff with time to spend making sure they get it (p. 112).

21b. Schaafsma, Carol. Review of Advances in Understanding Approval and Gathering Plans in Academic Libraries, in Library Resources \& Technical Services 15:557-8 (Fall 1971).

22. Spyers-Duran, Peter and Gore, Daniel, eds. Economics of Approval Plans. Westport, Conn.: Greenwood Press, 1972. (Proceedings of the Third International Seminar on Approval and Gathering Plans in Large and Medium-Size Libraries, West Palm Beach, February 17-19, 1971.)

Papers, unavailable at this writing, will include:

Anderson, LeMoyne, and Rebuldela, Harriet, a review of technical procedures to take advantage of the economics that approval plans offer. (See also entry no. 8a.)

-Axford, H. William, a study demonstrating the economies effected by blanket and approval plans. (See also entry no. 19.)

Gore, Daniel, plans for libraries with small budgets.

Gormley, Mark, the possibility of failure if the plans are not properly administered and monitored.

Lane, David O., the effects of approval plans on academic libraries.

Blanket order and approval plans have come to occupy a separate section in the reviews of acquisitions published annually by Library Resources \& Technical Services. Ranging from brief mention to reviews of the year's major articles, they are:

23. Dougherty, Richard M. "Cooperative and Blanket Acquisitions Plans," in "Year's Work in Acquisitions," 19: 150-1 (Spring 1965).

24. - "Automation of Acquisition Work," in "Acquisition-1965 in Review," 10:171 (Spring 1966).

25. — and Abigail McKinney. "The Nature and Scope of Acquisitions Work," in "Ten Years of Progress in Acquisitions: 1956-66," 11:292 (Summer 1967). 
26. Dahl-Hansen, Abigail, and Dougherty, Richard M. "Publisher Standing Order Plans," in "Acquisitions in 1967,” 12:179-80 (Spring 1968).

27. … "Approval Plans," in "Acquisitions Trends-1968," 13:376 (Summer 1969).

28. Fristoe, Ashby J., and Myers, Rose E. "Blanket Orders and Approval Plans," in "Acquisitions in 1969," 14:168-9 (Spring 1970).

29. - "Approval Plans and Blanket Orders," in "Acquisitions in 1970," 15:135 (Spring 1971).

There are packets of brochures, thesau$r i$, lists of publishers, and customers' manuals describing approval plans and related services available from vendors, and, in addition, their services are described in appendices in the seminars on approval and gathering plans. ${ }^{20,21}$ The following five offer plans for U.S. publishers:

30. Richard Abel \& Company, Box 4245, Portland, OR 97208 (20, p. 64-65, $119-29$; 21, p. 116-18, 137-52).

31. The Baker \& Taylor Company, 50 Kirby Avenue, Somerville, NY 08876 (21, p. 120-2, 157-8).

32. Edco-Vis Associates, Box 95, Verona, WI 53593.

33. Midwest Library Service, 11400 Dorsett Road, Maryland Heights, MO 63042 (21, p. 203-5).

34. Stacey's, Division of Bro-Dart, Inc., 15255 East Don Julian Road, City of Industry, CA 91747 (Bro-Dart's BooksComing-Into-Print program described in the seminar proceedings has been superseded by a science-technology plan at the Stacey division).

\section{Discussion: VENDORS}

Technical problems, aside from the selection process, are usually generalized and only briefly mentioned in the literature. They have been presented in detail in only two articles, Thom ${ }^{8}$ and Rouse. $^{12,21}$ A paper yet to be published, that of Anderson and Rebuldela, al- so discusses processing technicalities. ${ }^{22}$ Some of the vendor-related difficulties that complicate technical procedures are discussed here.

On the theoretical level an approval plan is an arrangement among three cooperating groups: publishers, vendors, and libraries. In practice, these are three centripetal forces.

The problems with publishers are well known: advertisements far in advance of publication, with title changes in the interim, postponed publication or unannounced cancellations; the proliferation of small publishers; the difficulty of reaching university departments and professional associations; the same book published here and abroad.

Libraries can be inefficient. They sometimes fail to adjust technical processing to accommodate the demands of an approval plan or make use of the conveniences the vendors offer; they are frequently slow in paying bills, placing heavy demands on the financial structure of the vendor; they fail to understand the limitations of an approval plan, producing subsequent misunderstanding by faculty and librarians alike; they sometimes fail their selection responsibilities; they force vendors to meet individual processing requirements, causing increased vendor overhead and subsequent higher costs for all libraries.

Vendors, by placing themselves between these two problem-prone groups are patently asking for their troubles. But they themselves are causing others. Beginning with advertising and promotion, they overstate their capabilities. Consider:

Books from all major publishers....

Each month [the company's] new publication . . . keeps university, college, and special libraries abreast of virtually all new books of interest to them.

You'll be dealing with one source for new books from more than 4,000 pub- 
lishers. This program applies to all books in the humanities or the sciences, continuations, and monographs by commercial and non-commercial publishers.

[The company] now supplies the books of more than 3,000 publishers. In fact [the company] will supply any U.S. book in print distributed through normal wholesale channels, including trade, University Press, text, reference and technical titles.

The tendency, even in this day of supposedly sophisticated consumers, is to look upon book jobbers as specialists in the matter of liberating books from publishers. Vendors' public statements lead one to expect that the situation is well in hand, especially when company representatives in person verbally support the advertising. One company, new to the approval-plan business, but which has obviously learned from its elders, says this: "We feel that it is unrealistic for any jobber to state that he obtains or warehouses, in fact that he even has contacts with all the United States Publishers, let alone Foreign Houses."

Approval plans for U.S. publications do not, because they cannot, supply "all" or "virtually all" of the academically pertinent output of " 4,000 publishers" or even " 3,000 publishers," major or otherwise. Vendors restrict their publisher coverage, as is verified by their lists of approval-plan publishers. Some specialty publishers will not work through dealers; but others that would are conspicuously missing from approval publisher lists. Wilden-Hart proposes persuading jobbers, using the Encyclopedia of Associations as a base, to handle the more difficult task of acquiring the publications of institutes and professional associations as an alternative to the costly gift-and-exchange systems libraries now depend upon (p. 404-5). ${ }^{13}$ "Jobbers are so conditioned to the commercial publishers who offer large discounts... that they have not had the perspicacity to see that the libraries are not in business to make a profit but to get those things they want" (p. 405).

Because approval plans/blanket orders do not blanket, prevailing opinion now is that approval plans must be monitored in the library by checking book receipts against Library of Congress proofs and other bibliographic tools. To insure complete coverage, even from the vendors' own publisher lists, this has to be done by the libraries, but it is not consistent with the companies' advertised and promotional claims. Furthermore, claiming a missed book will not always produce the book, in spite of the statement that "it is a simple matter to Xerox a copy of the request and to claim it against the plan. ... Such a move would insure the receipt of the desired item" (p. 345). 12a

There are four points to consider in regard to claiming:

1. A claim represents a book outside the vendor's routine. It is apparently extremely difficult to break into the normal processing to make a place for a stray book, especially in a computer system and even with a manual system. One vendor's representative said in a private meeting, "On any claim or back order we don't make a penny. The most expensive thing to do is send an [unscheduled] book."

2. Claiming is enormously expensive for a library. If a library receives a request for a book or discovers in monitoring that a book expected on an approval plan has not been received, the library logically will not order the book but will request the vendor to send it. It then probably files the request against the day the book arrives, and it must periodically check the file to see what has been outstanding too long. Over the months, because vendors do not supply all books and because claims do not produce all the known missed books, the file continuously enlarges. The library, ever hopeful, continues claiming.

Melcher estimates from an internal 
cost study that it takes ten cents to file a single form and another ten cents to pull the form from the file (p. 12, 21) -twenty cents for the filing operation for one claim. ${ }^{21 a}$ Add the number of claims and the number of times each is claimed, multiply by twenty cents, add the cost of Xeroxing and mailing, and add the unquantifiable costs of doing without the book in the meantime. In addition, the price of a book when announced can and does increase during the time it is repeatedly claimed and eventually produced or is ordered elsewhere.

3. The burden of seeing to it that all pertinent books arrive is on the library, not the vendor, who is advertising totality and selling the service. This is a fundamental point: the library staff, if it monitors its plan and tries to claim missed books, is in the unpaid employ of the vendor.

4. One of the charges against an approval plan, based on experience and the literature, is the uncertainty of knowing when, or even whether, a specific book will arrive "particularly when it had been specially requested" (Dudley, p. 322). ${ }^{11}$

An approval plan will produce most of the books, an accurate statement of the generality. But, how can a library know which specific title will be in the group that is volunteered and which title will be among those that are missed so that the library can take immediate action? Assuming that the responsibility for monitoring coverage is the library's and not the vendor's, Wilden-Hart proposes a cooperative plan: " . . if one library is assiduous in checking what it does not receive through approval plans, is then all the work involved for the benefit of one library and for one copy? ... By notifying the jobber that individual requests from libraries on approval plans may be significant items for other libraries, methods could be established to see that others benefit from the checking done. This could even be extended to sharing the bibliographical work in highly specialized fields ..." (p. 404).13 One library at least has repeatedly made the point to a vendor that a claim could represent multiple sales to other libraries, but we are now back to point no. 1 in this section: if the book does not enter the system routinely, it may never be entered.

Another aspect of the question of vendor responsibility is whether his representative should sell approval plans indiscriminately. Or, because through extensive travel he becomes knowledgeable about many kinds of libraries, can he be expected to act as a professional counselor? Should libraries be required to pass with high marks an approvalplan aptitude test? The agent knows his approval plan. Can he be expected to study the library's internal procedures and judge whether they are compatible? The library knows its own internal structure, its own individuality, but it must rely heavily on the agent's description of the approval plan to make a decision. Sheer increase in the number of customers cannot only overrun a vendor's staff so that it cannot support a representative's assurances, but the resulting problems caused by the mismatch can create complications and subsequent increased costs for the vendor and all his customers.

Errors in invoicing, duplicates, late receipt of books, failure to follow the profile, and casual bibliographic data are other grievances lodged against the vendor. They are a minor part of the process numerically, but they take a disproportionate amount of time to correct, and they drive costs up.

Vendors do not always follow their own advice. The president of one of the major vendors, in a speech before publishers in New York in 1962, was cited in Publishers' Weekly as follows:

[He] made the point that library budgets are for the most part static, 
and any way in which the expenses of library clerical work can be decreased means more money from the budget available for the purchase of books.

[He] mentioned that more than a few libraries have simply stopped ordering books from publishers who, through delays in shipping, incomplete orders, and unintelligible invoices, cause a mountain of paper work.

Whether books are supplied on approval or by order, by the publisher or through a vendor, the problems are the same, and the comments underscore the gap between the vendor's intent and his execution of bibliographic and accounting records. This is not always just a matter of inability to anticipate a Library of Congress entry; rather it is often a matter of an invoice that does not match its book or an invoice for a nonexistent book, requiring correspondence and special controls over the books and invoices until the matter can be resolved.

\section{Discussion: Research}

Most of the literature is descriptive; that is, the articles generalize about the theory and philosophy of an ideal approval plan or discuss procedures within a library. Those that have attempted statistical analysis include an in-house study at the University of California, ${ }^{5}$ Maher, ${ }^{9}$ Lane, ${ }^{10}$ Dudley, ${ }^{11}$ Evans, ${ }^{15}$ Axford, ${ }^{19,} 22$ and Atkinson. ${ }^{20}$

The need for further research has been stated by Wilden-Hart, ${ }^{13}$ Evans, ${ }^{15}$ and Axford, ${ }^{19,22}$ with specific suggestions for study given by Wilden-Hart and Evans.

Approval plans can be a tremendously helpful adjunct to a total acquisitions program. Another advantageous aspect, if it is followed up, is that they have an astonishing ability to throw into relief organizational weaknesses of the library and to amplify the need to consider collection-building throughout universitywide planning. But it is possible that an imaginatively conceived and vital selection tool will be lost to libraries if the complications, suspected or demonstrated, that they create in acquisitions processes and the subsequent increased costs should begin to be demonstrated in future research studies. Administrators who have accepted, and have stated publicly their acceptance of, the theory and philosophy of approval plans will not be able to accept the costs.

The following represent some aspects of approval plans that have received little attention in the literature; many studies have investigated the subject as generalities, but not all have been considered in specific relation to an approval plan.

-The relation of the approval plan to the on-going acquisitions program. How much does the money spent now on current acquisitions really reduce over the years the amount needed for retrospective purchases, considering incomplete coverage, delays in receipt of books, and the need for and futility of claiming?

-In-library costs of technical processing, especially for books not received: the costs of monitoring the program. Axford's study indicates the economy of an approval plan (for books received) but, because libraries themselves are a variable, his findings may not be applicable generally. ${ }^{19,22}$

-Prices of books; the total cost of an approval program and the cost by subject as an aid to budgeting, both library and departmental. Wilden-Hart said: "Research has yet to be done on the allocation of budgets by libraries using approval plans" (p. 403). ${ }^{13}$ Statistics based on the amount of publishing are not reliable for this purpose because for one reason or another not all books published are received; vendors' curtailed publisher lists will exclude many of them. The University of $\mathrm{Ne}$ braska and Florida Atlantic have been maintaining unpublished, therefore not 
generally available, statistical records (Axford, p. 369)..$^{19}$ One vendor cannot supply its representatives with cost-byclassification figures.

-Computers. Does, and how does, a computer system reduce the complicated technical detail an approval plan thrusts upon an acquisitions unit? How can unverified bibliographic data be handled to avoid complicating computer controls of the records? Boss says: "We have not found a way to use the computer to handle blanket orders" (p. 20). ${ }^{21}$ Also, is it possible for vendors to reduce scholarly publishing, which is bibliographically complex, to computer programming, which is inherently rigid and literal? One company has transferred its costly and unreliable computer-selection program to a previously organized manual system.

-Cataloging in publication. If an approval plan does produce books more rapidly than title-by-title ordering, some of them still wait in the library until the Library of Congress produces the cataloging and the cards. Presumably, cataloging in publication will speed library cataloging, but weaknesses are difficult to foresee. To take advantage of the cataloging printed in the book, one must have the book; to have the book, the publisher must send it to the vendor, and the vendor must send it to the library. Some vendors use as a way of announcing books a Library of Congress cataloging information service that is received several weeks in advance of proof-slip distribution; it would suffer from the same disadvantage of LC's late cataloging of some materials. The preproof-slip service suggests another area to explore: a comparison of the efficiency of vendors' announcement media.

-Selection. The subject has been thoroughly discussed in the literature, and Evans has expressed the need for further research, including "the need to examine the entire matter of acquisi- tions procedures in an objective and detailed manner. Too many of the decisions in acquisitions work are based on feelings and opinions rather than on evidence and fact" (p. 307).15

One extralibrary consideration can be expanded. Vendors have standing orders with publishers. Whether a vendor is working with all books of scholarly interest, or specializing in selected areas, he will have to describe to each publisher just what he has in mind-his own profile; the profile is then subject to interpretation by each publisher. The genesis of selection, obviously, is the editorial staff of the publishing houses, which must necessarily place economics before a library's esoteric needs. Approval-plan books thus move through three screenings before they ever appear in a shipment to a library.

Related to selection is the quality of publishing. A query frequently posed by faculty is whether approval plans with their supposed automatic library market promote excessive publishing of inconsequential books. One answer is probably no more than the publish-orperish dictum under which most faculties try to survive. In academic publishing the faculty itself supplies most of the manuscripts that later return as approval-plan submissions. The whole question of the publishing-selection process could be explored, in addition to the reverse effect of approval plans on publishing.

-Subject bibliographers. Some opinion holds that when bibliographers are used for difficult and esoteric areas, like Slavic studies, they can work to the disadvantage of general areas, like history, and therefore produce the same imbalance of the collection that an approval plan is supposed to correct. Is then one unit of a library's acquisitions organization canceling the efforts of another? Another aspect of the subject is suggested by Wilden-Hart, who proposes a study of how approval plans "are slowly 
changing the work of a subject bibliographer" (p. 405).13

-The long-term value of the books the approval plan produces, with its concomitant problems of shelving and subsequent weeding, which in turn are part of the costs. Studies using circulation during a fixed period as the base may not reliably measure this precise point because the focus of interest, especially in sociology and political science and possibly to an even greater extent in scientific and technological research, is constantly shifting. In addition, there is elapsed time before the appearance of bibliographies and indexes that stimulate continuing use. A book not used during the survey could be in demand later, although Evans says that some authors have found that future use is closely correlated with past use (p. 307). ${ }^{15}$

On the other hand, the whole point could be canceled by the philosophy that a new book is news, and that a library user should have any book available so that he is then able to decide for himself whether it is suitable for his purpose, now or in the future. If he decides not, the book's "use" will not be reflected in circulation figures, but it will certainly have been "used," and for a purpose. It suggests a survey of library policies and procedures for selection from approval-plan shipments.

Research will answer the questions, but then ways to apply the information must be found. Some writers are beginning to suggest cooperative ventures as possibilities. Vendors and libraries would surely gain by trying to implement such programs. Libraries need the vendors' expert assistance in dealing with publishers. Vendors could profit by the specialized bibliographic knowledge of the librarians and also by a greater understanding of the philosophical thinking their approval plans promote in libraries in contrast to the demanding logistical problems that must engage much of the vendors' efforts. An approval plan is a continuum; it is not a mutually exclusive two-step geographical process of shipping cartons of books from one spot and receiving them at another.

Wilden-Hart has outlined an interlibrary monitoring program and a plan to bring under control the publications of associations. ${ }^{13}$ A F. Schnaitter has proposed liaison-librarians to work with vendors at their locations (p. 348).12a There are others:

-The literature survey turned up two in-house studies: the University of California study of some of the mechanics and the University of Oklahoma study of vendor reliability. ${ }^{9}$ In addition to the University of Nebraska and Florida Atlantic statistical studies, there are undoubtedly others. A clearinghouse of such otherwise unavailable information could be established and lists published regularly for comparison among libraries and for points of departure for more generalized surveys.

-Another aspect of mutual libraryvendor understanding is described by the same company president quoted earlier; he "attributed many of the problems to a lack of communication between the publisher and the library purchaser, each of whom has his administrative requirements to fulfill, but seldom realizes the needs of the other."

As a way of implementing the need for better library-vendor communication, perhaps vendors would consider newsletters to their customers detailing the realities of publisher-vendor relations and of book-publishing economics and logistics. Descriptions of their own organization and procedures, with directories of personnel, would be helpful.

Librarians, in their relations with library users, deal with facts and with ideas of substance, not in unsubstantiated promotional claims. Because of their stock in trade and because of the unanimity of support for the approval- 
plan concept, librarians are psychologi- And as librarians learn more of their cally in a position to turn a vendor's spe- own internal specifics, they will in turn cial knowledge, if he will share it can- have practical information to share didly, into an informed effort to make with vendors. approval plans functionally acceptable. 